Ege Tıp Dergisi / Ege Journal of Medicine 2014;53(3):145-153

\title{
Pregabalinin lomber interlaminar epidural kortikosteroid enjeksiyonu uygulaması sonrası vizüel analog skala değerlerine etkisi
}

Pregabaline effect on visual analog scale values after lumbar inter-laminar epidural corticosteroid injection

\author{
Yektaş A Gümüş $\mathrm{F}$ Erkalp K Alagöl $\mathrm{A}$
}

Bağcılar Eğitim ve Araştırma Hastanesi, Anesteziyoloji ve Reanimasyon Kliniği, İstanbul, Türkiye

\section{Özet}

Amaç: İnterlaminar lomber epidural kortikosteroid enjeksiyonu (ILEKE) bel ağrısında kullanılan minimal invaziv bir tedavi yöntemidir. Bu çalışmada radikülopatisi olan disk hernili hastalarda İLEKE uygulamasında pregabalinin VAS değerlerine etkisini incelemeyi amaçladık.

Gereç ve Yöntem: Polikliniğimize başvuran ve ILEKE uygulanan 100 hastaya ait kayıtların retrospektif olarak incelenerek hastaların pregabalin alan Grup P ve almayan Grup Z olarak iki gruba ayrılmasıyla gerçekleştirildi. Vizüel analog skala (VAS) değerleri 1. hafta, 1-6. ay ve 1. yıl da değerlendirildi.

Bulgular: Grup P ve Grup Z de başlangıç VAS değerlerine göre 1. hafta, 1-6. ay ve 1. yılda VAS değerleri istatistiksel olarak anlamlı düşüktü. Grup P ile Grup Z karşılaştııılığında 1- 6. ay ve 1. yıl VAS değerleri Grup P de istatistiksel olarak anlamlı düşüktü. Grup P de işlem sonrası hasta memnuniyeti Grup Z ye göre istatistiksel olarak anlamlı yüksekti.

Sonuç: Pregabalin, İEKE uygulanan radikülopatili hastalarda VAS değerlerini uzun dönemde de anlamlı olarak düşürmekte, İLEKE uygulama sayısını azaltmakta ve işlem sonrası hasta memnuniyetini arttırmaktadır.

Anahtar Sözcükler: Disk hernisi, radikülopati, interlaminar lomber epidural kortikosteroid enjeksiyonu, pregabalin.

\section{Summary}

Aim: Inter-laminar lumbar epidural corticosteroid injection (ILECI) is a minimally invasive treatment method that is used in low-back pain. In this study, we aimed at investigating the effect of pregabalin administration on VAS values in patients with radiculopathy who have a disk hernia following administration of ILECI.

Materials and Methods: The records pertaining to 100 patients who presented to our outpatient clinic were retrospectively examined; the patients were divided into two groups: Group $P$, the patients who received pregabalin and Group $Z$, the patients who did not receive pregabalin. The visual analogue scale (VAS) scores were assessed in week 1, months 1-6 and year 1.

Results: The VAS scores of Group $P$ and Group $Z$ in week 1, months 1-6 and year 1 were lower than the baseline VAS scores at a statistically significant level. Based on a comparison between Group $P$ and Group $Z$, it was seen that the VAS scores in months 1-6 and year 1 were lower for Group $P$ at a statistically significant level. The postadministration patient satisfaction in Group $P$ was higher than Group $Z$ at a statistically significant level.

Conclusion: Pregabalin significantly reduces the VAS scores in patients with radiculopathy who have received $I L E C I$, it also decreases the frequency of ILECI administration and increases post-administration patient satisfaction.

Key Words: Disc herniation, radiculopathy, lumbar interlaminar epidural corticosteroid injection, pregabalin.

Yazışma Adresi: Abdülkadir YEKTAŞ

Bağcılar Eğitim ve Araştırma Hastanesi, Anesteziyoloji ve Reanimasyon Kliniği, Şanlıurfa, Türkiye

Makalenin Geliş Tarihi: 10.03.2014 Kabul Tarihi: 07.04.2014

\section{Giriş}

Bel ağrısı ciddi medikal ve sosyoekonomik sorunlara yol açan en önemli morbidite nedenlerinden biridir $(1,2)$. Endüstriyel toplumlarda bireylerin \%80'inin, hayatları boyunca en az bir kez bel ağrısı atağı yaşadığı gösterilmiştir (3). Spinal ağrı genel popülasyonun \%1545 'inde bel ağrısı ile en çok görülen ağrıdır (4,5). İntervertebral disk hernileri bel ağrısının sebeplerinden 
birisidir (6). Bel ağrısı şikayeti olanların bir çoğu tedaviye gerek duymazlar. Ancak \%2-8 kadarı tıbbi tedaviye gereksinim duyar ve konservatif tedaviye oldukça iyi yanıt verirler (7). Bel ağrılı hastaların büyük çoğunluğu ılımlı yatak istirahati, ilaç tedavisi, yaşam tarzı değişiklikleri, fizik tedavi ve eksersiz gibi konservatif tedavilerden yarar görürken, bu ağrıların yalnızca \% 5-8'i kronikleşmektedir $(3,8)$. Kronikleşen bu hastaların \% 14 'ü için cerrahi tedavi gerekebilmektedir (9). Cerrahi sonrası gelişen komplikasyonlar lomber disk hernisinin tedavisi için açık cerrahiye alternatif olan minimal invaziv tedavi yöntemlerini ön plana çıkarmıştır.

İnterlaminar lomber epidural kortikosteroid enjeksiyonu (ILEKE), minimal invaziv tedavi yöntemlerinden biridir. Epidural steroid enjeksiyonu akut ağrıda inflamasyonun baskılanmasında etkin bir yöntem olmakla beraber yöntem her hastada \%100 başarı sağlamamaktadır. Pregabalin, gama-amino-bütirik asidin (GABA) yapısal analoğudur, selektif olarak voltaj bağımlı kalsiyum kanallarının alfa 2 -delta subünitine bağlanırlar, analjezik, anksiyolitik ve antiepileptik etkilere sahiptirler (10).

Çalışmamızda; pregabalinin, radikülopatili hastalarda ILEKE uygulaması sonrasında, vizüel ağrı skalası (VAS) değerlerinde ve hasta memnuniyetinde olan değişikliklere etkilerini incelemeyi amaçladık.

\section{Gereç ve Yöntem}

$\mathrm{Bu}$ çalışma, hastane etik kurul onayı ve yazılı aydınlatılmış hasta onamları alındıktan sonra, 3 aydan uzun ve 6 aydan kısa süreli radiküler ağrılı disk hernisi nedeniyle, algoloji polikliniğine başvuran ve bu nedenle ILEKE yapılan 100 hastaya ait kayıtlara, tabakalı randomizasyon uygulanarak retrospektif incelemeyle gerçekleştirildi.

Çalışma verileri, Ocak 2011 - Mayıs 2013 arasında işlem yapılan 100 hasta dosyası incelenerek elde edildi.

ILEKE uygulaması: İşlemin uygulanacağı tüm hastalara, rutin olarak işlem öncesi İLEKE uygulaması ve komplikasyonları hakkında bilgi verildi. Yine hastalar VAS değerlendirilmesi hakkında da bilgilendirildi. Hastaların yaş, boy, kilo, cinsiyet bilgileri, semptom süreleri, nörolojik muayene bulguları, VAS kullanılarak ağrı değerlendirilmesi (VAS 0, hiç ağrı yok; VAS 10 bilinen en şiddetli ağrı) kaydedildi.

Hastaların rutin lomber MRI görüntülerinde (sagittal T1A, T2A ve aksiyal T2A) herniye diskin bulunduğu anatomik lokalizasyon (santral, parasantral), diskin özelliği (bulging, protrüzyon, ektrüzyon ve sekestresyon) değerlendirildi.

Çalışmaya dahil edilmeme kriterleri:

1. Foraminal ve ekstraforaminal anatomik lokalizasyona sahip herniye diskler (ekstrüdasyon, migrasyon ya da sekestrasyon görünümünün olması)

2. Daha önceden lomber cerrahi geçirmiş hastalar,
3. Floroskopi ile radyo-opak ilacın anterior epidural alanda yayılımını görmediğimiz vakalar,

4. İntraspinal disk kökenli olmayan bel ve bacak ağrıları (İntraspinal tümörler, epidural abse ve hematomlar, sinir enfeksiyonu, faset sendromu, spondiolistezis)

5. Ekstraspinal disk kökenli olmayan bel ve bacak ağrıları (Pelvis ve femur tümörleri, sakroilyak disfonksiyon, piriformis sendromu, sakroiliit ve seronegatif spondiloartropatiler, siyatik sinir dışı pelviste tuzak nöropatiler, miyofasial ağrı sendromları, trokanterik bursit, kalça osteoartriti, peroneal sinir sıkışması ve maralgia parestetika)

Çalışmaya dahil edilme kriterleri:

1. ASA I-II grubuna dahil olan,

2. 18-85 yaş arasında olan,

3. Lumbar disk hernisi (Bulging, Protrüzyon) olan,

4. En az 3-6 ay ağrı çekmiş ve medikal, fizik tedavi (davranışsal yöntemler, psikososyal düzenlemeler ve eksersiz programları) gibi medikal ve konservatif tedavi yöntemlerine yanıt vermeyen (VAS skorları 5 ve üstü olanlar),

5. Hastaların $L_{1}, L_{2}, L_{3}, L_{4}, L_{5}, S_{1}$ sinir köklerine uyan alanlarda duyu muayenesi yapıldı. $L_{1}, L_{2}, L_{3}, L_{4}, L_{5}, S_{1}$ sinir köküne uyan bölgelerde tutulum muayenesi yapılarak, ağrı olup olmadığına bakıldı. Klinik muayenede en az bir veya daha fazla sinir kökü tutulumu (radyolojik bulgularla uyumlu olan) saptanan ve şikayetleri radikülopatiyle uyumlu olan hastalar.

6. Bacak ağrısı bel ağrısından şiddetli olan (Laseque, Braggard, femoral sinir germe testi, Naffziger testi, Cram testi pozitif ) hastalar,

7. Grup P ve Grup Z de etkilenen sinir bölgesinde EMG bulgularının radikülopatiye işaret etmesi.

Çalışmaya dahil edilen hastalar, pregabalin başlanan ve başlanmayan olarak iki gruba ayrıldı. Pregabalin alan grup (Grup P) ve almayan grup (Grup Z) olarak adlandırıldı. Pregabalin alan gruptaki hastalara işlem yapılmadan 1 hafta önce, pregabalin $2 \times 75 \mathrm{mg}$ oral başlandı ve işlem için gün verildi, pregabaline işlem sonrası 1. aya kadar devam edildi. Her iki gruba da parasetamaol $325 \mathrm{mg}+$ tramadol $39.5 \mathrm{mg}$ ve tizanidin $3 \times 2 \mathrm{mg}$ işlem yapılana kadar kullanılmak üzere işlemden 1 hafta önce başlandı. İşlem uygulandıktan sonra tizanidin ve parasetamol+tramadol her iki grupta da kesildi.

Uygulama öncesi hastaların rutin kan tetkikleri teyit edildi ve uygulama günü standart açlık protokolüne göre işleme kabul edildiler. Hastalar işlem günü ameliyathaneye alındı, intravenöz damar yolu açıldı ve izotonik sodyum klorür solüsyonu takıldı. Damar yolu açıldıktan sonra, hastalar ameliyat masasına yan yatar pozisyonda alındı. Bütün uygulamalar lokal anestezi ve C-kollu floroskopi eşliğinde yapıldı. Olası komplikasyonları 
maskelememek için hiçbir hastaya sedasyon yapılmadı. Hastada radiküler ağrıya neden olan disk hernisinin olduğu seviye floroskopi altında işaretlendi. İşlemin planlandığı aralığa \%2'lik $5 \mathrm{ml}$ lidokain ile cilt, cilt altına infiltrasyon anestezisi uygulandı. On sekiz G Touhy iğnesi (Epidural minipack 473, Portex, UK) ile direnç kaybı yöntemi kullanılarak epidural aralığa girildi ve önarka pozisyonda iğne floroskopi ile görüntülendikten

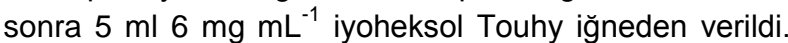
Epidurografi çekildi ve floroskopide iğnenin epidural aralıkta olduğu görülüp radyo opak ilacın anterior epidural aralıkta da (Resim-1) yayılımı görüldükten sonra $80 \mathrm{mg}$ triamsinolon asetat, $10 \mathrm{mg}$ izobarik bupivakain ve $6 \mathrm{~mL}$ serum fizyolojik toplam $10 \mathrm{~mL}$ olacak şekilde epidural aralığa verildi.

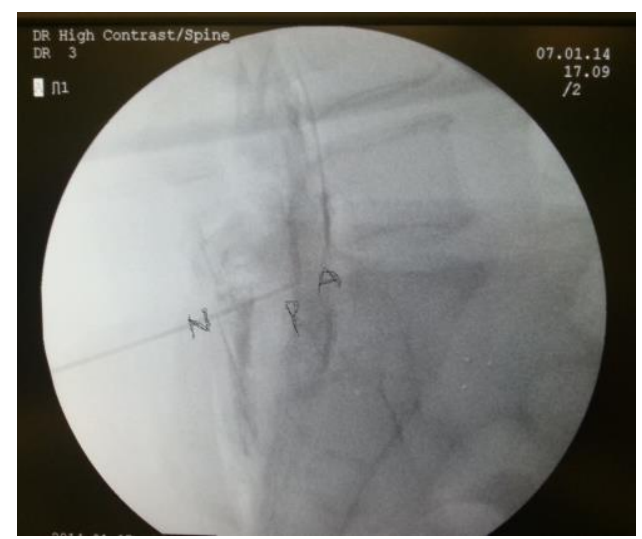

Şekil-1. İgnenin pozisyonu ve anterior-posterior epidura aralığın floroskopik görüntüsü.

A- Anterior epidural aralık

P- Posterior epidural aralık

$\mathrm{N}$ - İğne

Hastalarda, İLEKE sonrası 1. haftadaki, 1 ve 6 . aydaki ve 1. yıldaki VAS değerleri kaydedildi. Yirminci gündeki VAS değeri 4 ve altında ise hastanın işlemden fayda gördüğü düşünüldü. 20. gündeki VAS değeri 4 ün üzerinde ise hastaya işlem sonrası 25. günde aynı şartlarda 2. İLEKE uygulandı. İkinci enjeksiyon sonrası 1. haftadaki, 1 ve 6 . aydaki ve 1 . yıldaki VAS değerleri değerlendirildi. İkinci enjeksiyon sonrası 20. gündeki VAS değerleri halen 4 ün üzerinde olan hastalar beyin ve sinir cerrahisi değerlendirmesi istendi, ameliyat endikasyonu olmayanlarda medikal tedaviye devam edildi. İşleme bağlı gelişen komplikasyonlar kaydedildi. ILEKE sonrası hasta memnuniyet skoru olarak ise 4 puanlı sistem kullanıldı; 1- kötü, 2- orta, 3- iyi ve 4mükemmel.

Birincil ölçüm parametresi olarak hastalarda radyo-opak maddenin anterior epidural alanda yayılıp yayılmadığına bakıldı. İkincil ölçüm parametresi olarak 1. yıl VAS ağrı değerleri kullanıldı. Bu değerler uygulama öncesi değerler ile karşılaştırılarak İLEKE uygulamasının etkinliği yorumlandı, her iki gruptaki VAS ağrı değerleri karşılaştırılarak, pregabalinin VAS ağrı değerlerine etkinliği değerlendirildi.

\section{Istatistiksel Analiz}

Bu çalışmada tüm istatistiksel hesaplamalar bilgisayar ortamında SPSS version 11.5 for Windows paket programı yardımıyla değerlendirildi. Verilerin normal dağılıma uygunluğu için Kolmogorov-Smirnov testi kullanıldı. İstatistiksel değerlendirmelerde her bir grupta ILEKE uygulaması öncesi ve sonrası VAS değerleri Wilcoxon testi ile karşılaştırıldı. Cinsiyet ve aile durumu Fisher'in kesin ki kare testiyle değerlendirildi. Gruplarda kaç enjeksiyon yapıldığının değerlendirilmesinde ki-kare testi kullanıldı. Hastaların yaş, boy, vücut kitle indeksi, tedavisiz geçen gün sayısı, şikayet süreleri, gruplar arası bazal VAS değerleriyle 1. hafta, 1-6. ay ve 1. yıl VAS değerleri farklarının karşılaştırılması, hasta memnuniyeti, Mann-Whitney $U$ testi ile karşılaştırıldı, tüm veriler medyan (minimum-maksimum) olarak verildi. Tüm veriler için $p<0,05$ istatistiksel olarak anlamlı kabul edildi.

\section{Bulgular}

Hasta gruplarına ait cinsiyet, yaş, vücut kitle indeksi, evlilik durumları, tedavi uygulanmadan geçen süre ve şikayet süreleri özetlenmiştir (Tablo-1).

Grup P ile Grup Z arasında cinsiyet $(p=1,000)$, yaş $(p=0,072)$, vücut kitle indeksi $(p=0,295)$, evlilik durumları $(p=0,617)$, tedavi uygulanmadan geçen süre $(p=0,430)$ ve şikayet süreleri $(p=0,190)$ açısından istatistiksel olarak anlamlı farklılık yoktu. Gruplara ait hastaların iş durumları özetlenmiştir (Tablo-1). Grup P de hastaların çoğunluğunu ev hanımları oluşturmakta 2. sıradaysa aktif olanlar, Grup Z de hastaların çoğunluğunu aktif olanlar ve 2. sıradaysa ev hanımları bulunmaktadır. Tedavi uygulanmadan geçen süre her iki gruptaki hastalarda istatistiksel olarak benzerdi. Gruplardaki hastaların önceden aldığı tedaviler Tablo-1'de \% olarak verilmiştir.

Disk hernilerinin MRI görüntülerine göre anatomik yapıları ve seviyeleri verilmiştir (Tablo-2). Disk hernilerinin \%3.4'ü (6) $L_{1-2}$ de, \%7.39'u (13) $L_{2-3}$ de, $\% 17.04$ 'ü (30) $L_{3-4}$ de, \%43.78'i (77) $L_{4-5}$ de ve \%32.39'u (57) $\mathrm{L}_{5}-\mathrm{S}_{1}$ seviyesinde bulunmaktaydı. Disk hernilerinin \%82.39'ü (153) kadınlarda ve \%17.61'i erkeklerdeydi.

Disk hernilerinin kaç seviyede olduğu ve cinsiyetlere dağılımı verilmiştir (Tablo-3). Grup P de disk hernilerinin \%48'i (24) tek seviyede, \%28'i (14) çift seviyede, \%16'sı (8) 3 seviyede ve \%8'i (4) 4 seviyedeydi. Grup Z de disk hernilerinin \%52'si (26) tek seviyede, \%28'i (14) çift seviyede, \%18'i $\quad$ (9) 3 seviyede ve \%2'si (1) 4 seviyedeydi. 
Tablo-1. Demografik ve Klinik Özellikler.

\begin{tabular}{|c|c|c|c|}
\hline Özellikler & Grup P (n = 50) & Grup Z ( $n=50)$ & $\mathbf{P}$ \\
\hline Cinsiyet (Kadın/Erkek) n (\%) & $35(70) / 15(50)$ & $35(70) / 15(50)$ & 1.000 \\
\hline Yaş (Yıl) Medyan (Min-Maks) & $46(27-72)$ & $42(24-86)$ & 0.072 \\
\hline Vucut kitle indeksi $\left(\mathrm{kg} / \mathrm{m}^{2}\right)$ & $28.02(22.44-31.07)$ & $28.03(20.18-33.12)$ & 0.295 \\
\hline Evlilik durumu (Evli/Bekar) n (\%) & $49(98) / 1(2)$ & $47(94) / 3(6)$ & 0.617 \\
\hline İş durumu & n (\%) & n (\%) & \\
\hline Aktif & $11(22)$ & $23(46)$ & \\
\hline Ev hanımı & $26(52)$ & 18(36) & \\
\hline Hastalık izni & $3(6)$ & $3(6)$ & \\
\hline İşsiz & $5(10)$ & $2(4)$ & \\
\hline Emekli & $6(12)$ & $4(8)$ & \\
\hline Tedavi uygulanmadan geçen süre (gün) & $58(28-180)$ & $64(20-180)$ & 0.430 \\
\hline Şikayet süreleri (gün) & $138(90-180)$ & $145(90-180)$ & 0.190 \\
\hline Önceki tedaviler ${ }^{a}$ & n (\%) & n (\%) & \\
\hline NSAii & $32(64)$ & $34(68)$ & \\
\hline Parasetamol & $10(20)$ & $8(16)$ & \\
\hline Metamizol & $2(4)$ & $3(6)$ & \\
\hline Opioid & $2(4)$ & $1(2)$ & \\
\hline Antiepileptik ilaç & $1(2)$ & - & \\
\hline TCA & $24(48)$ & $22(44)$ & \\
\hline Benzodiazepin & $3(6)$ & $7(14)$ & \\
\hline Vit-B $-B_{6}-B_{12}$ & $24(48)$ & $32(64)$ & \\
\hline Diğer $^{b}$ & $27(54)$ & $22(44)$ & \\
\hline
\end{tabular}

${ }^{a}$ Daha öncesinde bir veya daha fazla tedavi alan hastalar

${ }^{b}$ Kortikosteroid kullananlar

Veriler medyan (minimum-maksimum) ve kategorik veriler $\mathrm{n}(\%)$ olarak verilmiştir.

Tablo-2. Disk Hernilerinin MRI Görüntülerine Göre, Anatomik Yapıları ve Seviyelere Dağılımı.

\begin{tabular}{|c|c|c|c|c|c|c|c|c|c|}
\hline & \multirow[b]{3}{*}{ n (\%) } & \multicolumn{4}{|c|}{ Grup P } & \multicolumn{4}{|c|}{ Grup Z } \\
\hline & & \multicolumn{2}{|c|}{ Kadın } & \multicolumn{2}{|c|}{ Erkek } & \multicolumn{2}{|c|}{ Kadın } & \multicolumn{2}{|c|}{ Erkek } \\
\hline & & $B$ & $\mathrm{P}$ & $\mathrm{B}$ & $\mathrm{P}$ & $B$ & $\mathrm{P}$ & $B$ & $\mathrm{P}$ \\
\hline$L_{1-2}$ & $6 \quad(3.4)$ & 1 & 2 & - & - & 1 & 2 & - & - \\
\hline $\mathrm{L}_{2-3}$ & $13(7.39)$ & 6 & - & - & - & 4 & 2 & - & 1 \\
\hline$L_{3-4}$ & $30(17.04)$ & 14 & 2 & 3 & 1 & 4 & 4 & - & 2 \\
\hline$L_{4-5}$ & 77 (43.78) & 22 & 6 & 4 & 4 & 25 & 7 & 4 & 5 \\
\hline $\mathrm{L}_{5}-\mathrm{S}_{1}$ & 57 (32.39) & 14 & 6 & 5 & 6 & 19 & 4 & 1 & 2 \\
\hline
\end{tabular}

Toplam kadın: 153 (\%82.39) Toplam erkek: 38 (\%17.61)

B: Bulging, P: Protrüzyon

Tablo-3. Kaç Seviyede Disk Hernisi Olduğunun Hastalara ve Cinsiyete Göre Dağılımı.

\begin{tabular}{|c|c|c|c|c|c|c|}
\hline & \multirow{2}{*}{\multicolumn{2}{|c|}{ Grup P }} & \multirow{2}{*}{\multicolumn{2}{|c|}{ Grup Z }} & \multirow{3}{*}{$\begin{array}{l}\text { Grup P } \\
\mathrm{n}(\%)\end{array}$} & \multirow{3}{*}{$\begin{array}{c}\text { Grup Z } \\
\mathrm{n}(\%)\end{array}$} \\
\hline & & & & & & \\
\hline & Kadın & Erkek & Kadın & Erkek & & \\
\hline 1 seviye & 19 & 5 & 16 & 10 & $24(48)$ & $26(52)$ \\
\hline 2 seviye & 8 & 6 & 12 & 2 & $14(28)$ & $14(28)$ \\
\hline 3 seviye & 5 & 3 & 7 & 2 & $8(16)$ & $9(18)$ \\
\hline 4 seviye & 3 & 1 & - & 1 & $4(8)$ & $1(2)$ \\
\hline
\end{tabular}


Tablo-4. Grup P ile Grup Z'ye Ait, Başlangıç VAS Değerleri ve Başlangıç VAS Değerleriyle 1.hafta, 1-6. ay ve 1. yıl VAS Değerlerinin Farklarının Karşılaştıııması.

\begin{tabular}{l|c|c|c}
\hline & Grup P $(\mathbf{n}=\mathbf{5 0})$ & Grup Z $(\mathbf{n = 5 0})$ & $\mathbf{p}$ \\
\hline Başlangıç VAS skoru & $8(7-10)$ & $8(7-10)$ & 0.531 \\
\hline 1. Hafta VAS skoru & $5(-1-10)$ & $4(0-10)$ & 0.258 \\
\hline 1. Ay VAS skoru & $5(-1-10)$ & $3(-3-8)$ & $<0.001$ \\
\hline 6. Ay VAS skoru & $5(-1-8)$ & $3(-3-7)$ & $<0.001$ \\
\hline 1. Yıl VAS skoru & $5(-1-8)$ & $2(-3-6)$ & $<0.001$ \\
\hline
\end{tabular}

Veriler medyan (minimum-maksimum) olarak verilmiştir.

Grup P ile Grup Z ye ait, başlangıç VAS değerleri ve başlangıç VAS değerleriyle 1.hafta, 1-6. ay ve 1. yıl VAS değerlerinin farklarının karşılaştırılması verilmiştir. (Tablo-4). Grup P ve Grup Z de başlangıç VAS değerleri $(p=0,531)$ ve başlangıç VAS değerleriyle 1 . hafta VAS değerleri arasındaki farkın $(p=0,258)$ karşılaştırımasında istatistiksel olarak anlamlı farklılık olmadığı görüldü. Ancak 1-6. ay $(p<0.001)$ ve 1 . yıl $(p<0.001)$ VAS değerlerinin farkları karşılaştıııldığında istatistiksel olarak anlamlı farklılık olduğu görüldü.
Gruplara ait başlangıç VAS değerleriyle 1. hafta, 1-6. ay ve 1. yıl VAS değerleri karşılaştırılmış ve her iki grupta da başlangıç VAS değerleriyle 1 . hafta $(p<0.001), 1-6$. ay $(p<0.001)$ ve 1 . yıl VAS $(p<0.001)$ değerleri arasında istatistiksel olarak anlamlı farklılık olduğu görülmüştür (Tablo-5).

Hastaların epidural kortikosteroid yapıldıktan sonra işlem esnasındaki memnuniyetleri verilmiş ve Grup P ile Grup $Z$ arasında istatistiksel olarak anlamlı farklılık olduğu görülmüştür $(p<0.001)$ (Tablo-6).

Tablo-5. 1. hafta, 1. ay, 6. ay ve 1. yıl VAS Değerlerinin Baseline VAS Değerlerine Göre p Değerleri.

\begin{tabular}{|c|c|c|c|c|c|c|c|c|c|}
\hline & $\begin{array}{l}\text { Baseline } \\
\text { VAS }\end{array}$ & $\begin{array}{c}\text { 1. Hafta } \\
\text { VAS }\end{array}$ & $\begin{array}{l}\text { 1.Ay } \\
\text { VAS }\end{array}$ & 6.Ay VAS & 1.YIl VAS & \multicolumn{4}{|c|}{$\mathbf{p}$} \\
\hline & Medyan & Medyan & Medyan & Medyan & Medyan & Baseline & Baseline & Baseline & Baseline \\
\hline & $\begin{array}{l}(\min - \\
\max )\end{array}$ & $\begin{array}{l}(\min - \\
\max )\end{array}$ & $\begin{array}{l}(\min - \\
\max )\end{array}$ & $\begin{array}{l}(\min - \\
\max )\end{array}$ & $\begin{array}{l}(\min - \\
\max )\end{array}$ & 1.hafta & 1.Ay & 6.Ay & 1. YII \\
\hline $\begin{array}{l}\text { Grup P } \\
(n=50)\end{array}$ & $8(7-10)$ & $2(0-8)$ & $3(0-10)$ & $3(0-10)$ & $3(0-10)$ & $<0.001$ & $<0.001)$ & $<0.001$ & $<0.001$ \\
\hline $\begin{array}{l}\text { Grup Z } \\
(n=50)\end{array}$ & $8(7-10)$ & $4(0-7)$ & $5(2-10)$ & $5,5(3-10)$ & $6(4-10)$ & $<0.001$ & $<0.001)$ & $<0.001$ & $<0.001$ \\
\hline
\end{tabular}

Tablo-6. Grup P ile Grup Z'deki Hastalara Epidural Kortikosteroid Uygulandıktan Hemen Sonra Hasta Memnuniyetinin Karşılaştııılması.

\begin{tabular}{l|c|c|c}
\cline { 2 - 4 } & Grup P (n=50) & Grup Z (n=50) & $\mathbf{p}$ \\
\hline Hasta memnuniyeti & $3(1-4)$ & $2(1-4)$ & $<0.001$ \\
\hline
\end{tabular}

Veriler medyan (minimum-maksimum) olarak verilmiştir.

Tablo-7. Grup P ve Grup Z'de VAS Skorlarına Göre Tekrarlanan Epidural Kortikosteroid Enjeksiyonu Sayılarının Karşılaştırılması.

\begin{tabular}{l|c|c|c}
\cline { 2 - 4 } & Grup P $(\mathbf{n}=\mathbf{5 0})$ & Grup Z (n=50) & p \\
\hline $\begin{array}{l}\text { Epidural kortikosteroid } \\
\text { enjeksiyonu sayısı (1/2) }\end{array}$ & $43 / 7$ & $18 / 32$ & $<0.001$ \\
\hline
\end{tabular}

Gruplardaki epidural kortikosteroid enjeksiyonu sayısının karşılaştırılması verilmiş ve Grup P ile Grup Z arasında istatistiksel olarak anlamlı farklılık olduğu görülmüştür $(p<0.001)$ (Tablo-7). Grup Z de 33 hastaya Grup P de ise 7 hastaya 2 . kez enjeksiyona gerek kalmıştır.

Grup $Z$ de 2 hastada işlem yapıldıktan sonraki 17 . ayda beyin ve sinir cerrahisinin değerlendirmesi sonrası cerrahi gerekti.
Grup P'de 2 hastada yüzde flushing gelişmiş, Grup Z'de 3 hastada vazovagal semptom ve 4 hastada yüzde flushing gelişmiştir.

\section{Tartışma}

Çalışmamızda Grup P ve Grup Z de hastaların başlangıç VAS değerleriyle 1. hafta, 1-6. ay ve 1. yıl VAS değerleri arasında istatistiksel olarak anlamlı farklılık vardı ve her iki grupta da 1. hafta, 1-6. ay ve 1. yıl VAS değerleri 
başlangıç VAS değerlerine göre düşüktü, VAS değerleri, sırasıyla Grup P de 1.haftada $\% 52,50,1$. ayda $\% 63,75$, 6. ayda $\% 61,75$ ve 1. yılda $\% 61,25$ düşmüştür. Grup Z de ise VAS değerleri, sırasıyla 1. haftada \%66,50, 1. ayda \%37, 6. ayda \%32 ve 1. yılda \%23,75 azalmıştır (Tablo-5). Ancak Grup P ile Grup Z de başlangıç VAS değerleriyle 1-6. ay ve 1. yıl VAS değerleri arasındaki farklarda da istatistiksel olarak anlamlı farklılık vardı ve Grup P de bu dönemlerde VAS değerleri arasındaki fark daha yüksekti (Tablo-5). Bu sonuçlar, ILEKE uygulamasının VAS değerlerini kısa dönemde ileri düzeyde, uzun dönemde ise orta düzeyde düşürdüğünü göstermiş olup, pregabalinin tedaviye eklenmesinin, VAS değerlerini kısa dönem ve uzun dönemde de ileri düzeyde düşürdüğünü göstermektedir.

Abdi ve ark. (11), lumbar transforaminal epidural steroid (TFESE) uygulamasının etkinliğini 6 haftaya kadar iyi 6 haftadan sonra orta derecede yararlı olarak tanımlamaktadır. Etkinlik açısından 6 aya kadar lumbar TFESE uygulaması 4 randomize kontrollü klinik calışmada etkili, $(12,13) 6$ aydan sonra 2 calışmada etkili, (13,14) 1 calışmada etkisiz (12), 1 calışmada ise yetersiz (15) olarak değerlendirilmiştir. Grup P de 1. yıl sonunda da İLEKE uygulaması etkili olarak bulunmuştur, VAS değerleri \%61.25 düşmüştür. Grup Z de VAS değerleri 1. yıl sonunda ancak \%23.75 azalmıştır (Tablo-5).

Literatürde İLEKE ve TFESE uygulamasına bağlı komplikasyon olarak infeksiyon, hematom, ilacın intravasküler gitmesi, sinir travması, subdural enjeksiyon, hava embolisi, intradiskal giriş, idrar retansiyonu, radyasyona maruziyet ve hipersensitivite olarak bildirilmiştir (16). Her iki grupta da hastalarda vazovagal reaksiyon ve yüzde geçici flushing dışında komplikasyon gelişmemiştir.

Epidural sterorid enjeksiyonları ve selektif lomber sinir kökü blokları, spinal ağrı ve radikülopatinin tanı ve tedavisinde floroskopi eşliğinde uygulanan minimal invaziv girişimlerdir (17). Yapılan bir meta analizde, steroid ve lokal anestezikler ile disk herniasyonuna sekonder radikülitisde floroskopi altında, lomber epidural kortikosteroid enjeksiyonu, bu yazıdaki kanıtlar temel alındığında iyidir, yalnız lokal anestezik de makul bir etkinlik oluşturur. Lokal anestezik ve steroid, spinal stenozisin neden olduğu radikülitis için uygun bir tedavidir, steroidli ya da steroidsiz lokal anestezik disk hernisiz aksiel ağrıda da uygulanabilir (18). Çalışmamızda da steroid lokal anestezik karışımı radikülopatili disk hernisi olan hastalarda etkili bir tedavi oluşturmuştur (Tablo 4-5). Yapılan bir çalışmada lomber disk hernili ya da radikülitisli hastalar iki gruba ayrılmış ve ilk gruba yalnız lokal anestezik 2. gruba lokal anestezik ve steroid karışımı verilmiş Grup I de \%75 hastada Grup II de \%86 hastada İLEKE ile rahatlama olmuştur. Kontrollü çalışmalarda çoğu alt grup analizi göstermiştir ki kontrol hastalarıyla epidural kortikosteroid uygulanan hastalar arasında cerrahi oranlar arasında farklılık yoktur bununla beraber, omurga cerrahları tarafından yapılan randomize çalışmalarda, bazı hastalarda epidural steroid enjeksiyonunun stratejik kullanımı ameliyata engel olabilir (19). Çalışmamızda 1. yıl sonunda Grup P de VAS değerleri \%61.25 düşmüştür (Tablo-5). Bir yıllık izlemlerde İLEKE, steroid-lokal anestezik karışımı, yalnız lokal anestezik ile karşılaştıııl-dığında daha üstündür (20). Çalışmamızda sadece steroid ve lokal anestezik karışımı kullanılmış ve 1 . yıl sonunda VAS değerleri Grup P'de \% 61.25 ve Grup Z de \% 23.75 azalmıştır (Tablo-5).

Epidural steroid enjeksiyonu (ESE), epidural boşluktaki inflamasyonu azaltarak etkilenmiş sinir köküne bağlı oluşan ağrıyı azaltabilir ancak radiküler ağrıda ESE'nun kullanımı halen tartışmalıdır (21). Steroidler direkt ya da dolaylı yoldan prostaglandinler, arakidonik asit ve fosfolipaz A2 gibi inflamasyon ajanlarının yapımını ve salınımını inhibe ederler. İnflamasyon nedeniyle lökositler endotel duvarına tutunarak vasküler geçirgenliği arttırırlar ve doku ödemine neden olurlar. Steroidler aynı zamanda bu lökositlerin damar duvarına tutunmasını da azaltıcı etki gösterirler. Böylece akut inflamasyon inhibe edilir ve kronikleşmesi önlenir (22-25). İnflamasyonun süresi uzadıkça radikülopati belirgin hale gelir. ESE'de başarıyı belirleyen önemli faktör, anatomik değişikliklerin yoğunluğundan bağımsız olarak inflamasyon süresidir. Pek çok çalışmada radiküler ağrının başlangıçtan itibaren 3 ay içinde tedavisinin ESE ile planlanması kronik süreçle karşılaştırıldığında daha faydalı klinik sonuçların geliştiğini göstermektedir $(25,26,27)$. Bizde çalışmamızda 3-6 ay arasında radikülopati semptomları olan lumbal disk hernili hastalara ILEKE uyguladık ve kortikosteroidin antiinflamatuar etkilerinden yararlanmayı planladık (Tablo-1). Grup P ve Grup Z'nin her ikisinde de başlangıç VAS değerlerine göre 1. hafta, 1-6. ay ve 1. yıl VAS değerleri istatistiksel olarak anlamlı düşüktü ve bu etkiden yararlandığımızın göstergesiydi (Tablo-5).

Weiner ve Fraser, lomber disk hernisine bağlı ciddi radikülopatisi olup konservatif tedaviye yanıt vermeyen ve tek seçenek olarak cerrahi önerilen 28 hastada TLESE'nin etkinliğini araştırmışlar (28). Ortalama 3.4 (110) yıllık takip sonrasında üç hasta cerrahi olurken, 28 hastanın 22'sinin cerrahiye intiyaç kalmadan dramatik olarak ağrılarında tam ya da tama yakın azalma olduğu bildirilmiştir. Hasta grubumuz da radikülopatisi olup konservatif tedaviye cevap vermeyen hastalardı (Tablo-1). Biz epidural kortikosteroidi interlaminar teknikle uyguladık. Candido ve ark. tarafından yürütülen ilginç bir çalışmada (29), parasagittal interlaminar teknik (PIL) ile transforaminal (TFESE) teknik karşılaştırılmıştır. Birincil ölçüm parametresi olarak uygulama anındaki anterior bölgeye opak maddenin yayılımını, ikincil ölçüm parametresi olarak ise 6 . ayın sonundaki analjeziyi temel 
almışlardır. İki tekniğin analjezi üzerinde bir farkının olmadığını, ancak PIL tekniği ile tüm hastalarda ventral yayılımın başarıldığını belirtmişlerdir (\%100'e karşın \%75). Sonuç olarak, PIL tekniğinin TFESE'ye göre daha üstün bir yöntem olduğunu söylemişlerdir. Çalışmamızda da uyguladığımız teknikte birincil ölçüm parametresi olarak opak maddenin anterior epiduralda yayılımı gözlenmiştir. $\mathrm{Bu}$ anlamda sonuçlarımız Weiner ve Fraser'ın yaptığı çalışmanın sonuçları ile benzerlik göstermektedir (28). Çalışmamızda hastaların hepsi 1 yıl takip edildi, 1. yıl sonunda Grup P ve Grup Z de VAS değerleri başlangıç VAS değerlerine göre istatistiksel olarak anlamlı düşüktü (Tablo-5). Grup Z de 2 hasta 1 . yıl sonunda ameliyat olmak zorunda kaldı.

Epidural steroid enjeksiyonu, epidural boşluktaki inflamasyonu azaltarak etkilenmiş sinir köküne bağlı oluşan ağrıyı azaltabilir ancak radiküler ağrıda epidural steroid uygulamasının yeri halen tartışmalıdır (5). Radiküler ağrı hem nosiseptif hem de nöropatik komponenti olan mikst tip bir ağrıdır. Nosiseptif komponenti epidural steroid uygulaması ile tedavi edilebilir ancak nöropatik komponentinin tedavi edilmemesi bu başarısızlığın nedenlerinden biridir. Bel ağrılı çoğu hastada ağrı köken olarak nöropatik mekanizmalıdır ve bu tip ağrı \%10-19'dur (30,31). Nöropatik ağrının suboptimal tedavisine, hastanın hastalığı katkıda bulunur (32,33). Bununla birlikte nöropatik ağrı için sırasıyla uygulanan ilaç tedavileri mevcuttur; sırasıyla antidepresan, tramadol, opioid ve değişik antiepileptik ilaçlar önerilmiştir. Bunlar ışığında etkinlilik ve tolerabilite arasındaki uyum, gabapentin ve pregabalinin, nöropatik komponent ile olan periferik ağrı için tedavide ilk seçenek olabileceğini göstermiştir (34).

Pregabalin diyabetik nöropatili hastalarda ağrıyı \%39-48 $(35,36)$, postherpetik nevraljide \%28-50 $(37,38)$ ve spinal kort hasarlanması ile olan santral nöropatik ağrıda ise \%22 (39) azaltmıştır.

Grup P de VAS değerleri sırasıyla 1.haftada \%52.5, 1. ayda \%63.75, 6. ayda \%61.75 ve 1. yılda \%61.25 azalmıştır (Tablo 4-5).

Pregabalinin nöropatik ağrıda efektif doz aralığı 150-600 mg gün ${ }^{-1}$ dür (40). Randomize klinik bir çalışmada, periferik diyabetik nöropatik ağrıda ve postherpetik nevraljide iki eşit dozda toplam $372 \mathrm{mg} \mathrm{gün}^{-1}$ olarak uygulanmıştır (40). Biz çalışmamızda pregabalinin günlük dozunu alt sınırda tuttuk. Ancak bu dozda da Grup P de VAS değerlerinin Grup Z ye göre 1-6. ay ve 1 . yıl da istatistiksel olarak anlamlı düştüğü sonucuna ulaştık (Tablo-4) (5).
Preoperatif anksiyetenin postoperatif ağrı denetiminde rol oynayan olaylar zincirinde kritik bir role sahip olduğu belirtilmiştir (41).

Pregabalinin anksiyolitik etkinliği de vardır (10). Çalışmamızda da pregabalin alan grupta epidural kortikosteroid uygulaması sonrası hasta memnuniyeti Grup P'de istatistiksel olarak anlamlı yüksek bulunmuştur (Tablo-6). Pregabalin servikal ve lumbosakral radikülopati ile seyreden nöropatik ağrıda morbiditeyi azaltır ve hastanın genel durumunu düzeltir (41). Yaptığımız çalışmada da pregabalin alan grupta 1 yıllık takip sonucunda hastaların VAS değerleri Grup Z ye göre istatistiksel olarak anlamlı düşük bulunmuş, hastalarda morbidite oluşmamıştır (Tablo-4).

Pregabalin beyin ve medulla spinaliste aktiviteyi azaltır ve analjezik etkileri viseral ağrıdaki patolojiden bağımsızdır. Viseral ve somatik ağrıda, santral nosiseptif hipereksitabilitede azalma, pregabalinin beyin ve spinal sisteme ortak etkisi ile olur (42).

Yapılan bir hayvan çalışmasında, ratlarda pregabalinin antiinflamatuar ve anti apopitotik etkisi histokimyasal ve biyokimyasal yöntemlerle defalarca gösterilmiştir (43). Yaptığımız çalışmada da Grup P de VAS değerlerinin 16. ay ve 1. yılda Grup $Z$ ye göre daha düşük olmasında, pregabalinin antiinflamatuar ve anti apopitotik etkisinin olması muhtemeldir (Tablo-4). Hastalara uygulanan epidural kortikosteroid enjeksiyon sayısı da Grup P de Grup $Z$ ye göre istatistiksel olarak anlamlı düşük bulunmuştur (Tablo-7). Pregabalinin antiinflamatuar ve antiapopitotik etkinliğinin epidural kortikosteroid uygulama sayısını düşürmesi muhtemeldir.

Çalışmanın retrospektif olması, nöropatik ağrının değerlendirilmesine ait herhangi bir skala kullanılmaması, tedavinin günlük yaşam aktiviteleri ve yaşam kalitesi üzerine etkilerinin değerlendirilmemesi, sadece VAS değerlerine bakılmış olması çalışmamızın eksiklikleridir.

\section{Sonuç}

ILEKE, radikülopatisi olan hastalarda kısa dönemde VAS değerlerini düşürmekte etkilidir. Uzun dönemde ise etkinliği düşüktür. Lumbar epidural kortikosteroid uygulanmasında işlemden 1 hafta önce tedaviye pregabalin eklenmesi ve işlem sonrası 1. aya kadar pregabalin tedavisine devam edilmesi VAS değerlerini kısa dönemde olduğu gibi uzun dönemde de etkili bir şekilde düşürmektedir.

\section{Kaynaklar}

1. Weinstein SM, Herring SA. Lumbar epidural steroid injection. Spine J 2003;3(3):37-44.

2. Manchikanti L. Transforaminal lumbal epidural injection. Pain Physician 2000;3(4):374-98. 
3. Carey TS, Garrett JM, Jackman AM. Beyond the good prognosis. Examination of an inception cohort of patients with chronic low back pain. Spine 2000;25(1):115-20.

4. Lawrense RC, Helmick CG, Arnett FC, et al. Estimates of the prevalance of arthritis and selected musculoskeletal disorders in the United states. Arthritis Rheum 1998; 41(5):778-99.

5. Elliott AM, Smith BH, Penny KI, Smith WC, Chambers WA. The epidemiology of chronic pain in the comminity. Lancet 1999;354(9):1248-52.

6. Jeong HS, Lee JW, Kim SH, Mjung JS, Kim JH, Kang HS. Effectivenes of transforaminal epidural steroid injection by using a preganglionic approach: A prospective randomized controlled study. Radiology 2007;245(2):584-90.

7. Klenerman L, Slade PD, Stanley IM, Pennie B, Reilley JP, Atchison LE. The prediction of chronicity in patients with an acute attack of low back pain in a general practice setting. Spine 1995; 20(4):478-84.

8. Van Zundert j, Van Kleef M. Low back pain: From algorithm to cost-effectiveness? Pain Pract 2005;5(3):179-89.

9. Bush K, Cowan N, Katz DE, Gishen P. The natural history of sciatica assosiated with disc patology. A prospective study with clinical and independent radiologic follow-up. Spine 1992;17(10):1205-12.

10. Tassone DM, Boyce E, Guyer J, Nuzum D. Pregabalin: A novel gamma-aminobutyric acid analogue in the treatment of neuropathic pain, partial-onset seizures, and anxiety disorders. Clin Ther 2007;29(1):26-48

11. Abdi S, Datta S, Lucas LF. Role of epidural steroids in the management of chronic spinal pain: A systematic review of effectiveness and complications. Pain Physician 2005;8(1):127-43.

12. Karppinen J, Ohinmaa A, Malmivaara A, et al. Cost effectiveness of periradicular infiltration for sciatica: Subgroup analysis of a randomized controlled trial. Spine 2001;26(23):2587-95.

13. Vad VB, Bhat AL, Lutz GE, Cammisa F. Transforaminal epidural steroid injections in lumbosacral radiculopathy: A prospective randomized study. Spine 2002;27(1):11-6.

14. Riew KD, Park JB, Cho YS, et al. Nerve root blocks in the treatment of lumbar radicular pain. A minimum five-year follow-up. $J$ Bone Joint Surg Am 2006;88(8):1722-5.

15. Jeong HS, Lee JW, Kim SH, Myung JS, Kim JH, Kang HS. Effectiveness of transforaminal epidural steroid injection by using a preganglionic approach: a prospective randomized controlled study. Radiology 2007;245(2):584-90.

16. Goodman BS, Posecion LWF, Mallempati S, Beyazitoglu M. Complication and pitfalls of lumbar interlaminar and transforaminal epidural injections. Curr Rev Musculoskeletal Med 2008;1(3-4):212-22.

17. Eckel TS, Bartynski WS. Epidural steroid injections and selective nerve root blocks. Tech Vasc Interv Radiol 2009;12(1):11- 21.

18. Benyamin RM, Manchikanti L, Parr AT, et al. The effectiveness of lumbar interlaminar epidural injections in managing chronic low back and lower extremity pain. Pain Physician 2012;15(4):363-404.

19. Cohen SP, Bicket MC, Jamison D, Wilkinson I, Rathmell JP. Epidural steroids: A comprehensive, evidence-based review. Reg Anesth Pain Med 2013;38(3):175-200.

20. Manchikanti L, Singh V, Cash KA, Pampati V, Falco FJ. The role of fluoroscopic interlaminar epidural injections in managing chronic pain of lumbar disc herniation or radiculitis: A randomized, double-blind trial. Pain Pract 2013;13(7):547-58.

21. Koes BW, Scholten RJ, Mens JM, Bouter LM. Efficacy of epidural steroid injections for low-back pain and sciatica: A systematic review of randomized clinical trials. Pain 1995;63(3):279-88.

22. Olmarker K, Rydevik B, Holm S. Edema formation in spinal nerve roots induced by experimental, graded compression. An experimental study on the pig cauda equina with special reference to differences in effects between rapid and slow onset of compression. Spine 1989;14(6):569-73.

23. Rydevik B, Brown MD, Lundborg G. Pathoanatomy and pathophysiology of nerve root compression. Spine 1984;9(1):7-15.

24. McLain RF, Kapural L, Mekhail NA. Epidural steroid therapy for back and leg pain: Mechanisms of action and efficacy. Spine $J$ 2005;5(2):191-201.

25. Boschier CA, Glitin MG. Epidural steroid injections. In: Raj PP (ed). Textbook of regional anesthesia. New York: Churchill Livingstone; 2002: 687-702.

26. Caretta S, Laclaire R, Marcoux S, Morin F, Blaise GA, St-Pierre A. Epidural steroid injections for sciatica due to herniated nucleus pulposus. N Eng J Med 1997;336(23):1634-40.

27. Watts RW, Silagy CA. A meta-analysis on the efficacy of epidural corticosteroids in the treatment of sciatica. Anaesth Intensive Care 1995;23(5):564-9.

28. Weiner BK, Fraser RD. Foraminal injection for lateral lumbar disc herniation. J Bone Joint Surg Br 1997;79(5):804-7.

29. Candido KD, Raghavendra MS, Chinthagada M, Badiee S, Trepashko DW. A prospective evaluation of iodinated contrast flow patterns with fluoroscopically guided lumbar epidural steroid injections: The lateral parasagittal interlaminar epidural approach versus the transforaminal epidural approach. Anesth Analg 2008;106(2):638-44.

30. Carey TS, Evans AT, Hadler NM, et al. Acute severe low-back pain. A population-based study of prevalance and care-seeking Spine 1996;21(3):339-44.

31. Berger A, Dukes EM, Oster G. Clinical characteristics and economic costs of patients with painful neuropathic disorders. J Pain 2004;5(3):143-9.

32. Tolle $T, X u X$, Sadosky AB. Painful diabetic neuropathy: A cross-sectional survey of health state impairment and treatment patterns. J Diabetes Complications 2006;20(1):26-33.

33. Van Seventer R, Sadosky A, Lucero M, Dukes E. A cross-sectional survey of health state impairment and treatment patterns in patients with postherpetic neuralgia. Age Ageing 2006;35(2):132-7.

34. Finnerup NB, Otto M, McQuay HJ, Jensen TS, Sindrup SH. Algorithm for neuropathic pain treatment: An evidence based proposal. Pain 2005;118(3): 289-305.

35. Richter RW, Portenoy R, Sharma U, Lamoreaux L, Bockbrader H, Knapp LE. Relief of painful diabetic peripheral neuropathy with pregabalin: A randomized, placebo-controlled trial. J Pain 2005;6(4):253-60.

36. Dworkin $\mathrm{RH}$, Corbin AE, Young JP Jr, et al. Pregabalin for the treatment of postherpetic neuralgia: A randomized, placebocontrolled trial. Neurology 2003;60(8):1274-83. 
37. Van Seventer R, Feister HA, Young JP Jr, Stoker M, Versavel M, Rigaudy L. Efficacy and tolerability of twice-daily pregabalin for treating pain and related sleep interference in postherpetic neuralgia: A 13-week, randomized trial. Curr Med Res Opin 2006;22(2):375-84

38. Siddall PJ, Cousins MJ, Otte A, Griesing T, Chambers R, Murphy TK. Pregabalin in central neuropathic pain associated with spinal cord injury: A placebo-controlled trial. Neurology 2006;67(10):1792-800.

39. Saldaña MT, Navarro A, Pérez C, Masramón X, Rejas J. Patient-reported-outcomes in subjects with painful lumbar or cervical radiculopathy treated with pregabalin: evidence from medical practice in primary care settings. Rheumatol Int 2010;30(8): 100515.

40. Freynhagen R, Strojek K, Griesing T, Whalen E, Balkenohl M. Efficacy of pregabalin in neuropathic pain evaluated in a 12 week, randomised, double-blind, multicentre, placebo controlled trial of flexible- and fixed-dose regimens. Pain 2005;115(3):254-63.

41. Kain ZN, Sevarino F, Pincus S, Alexander GM, Wang SM, Ayoub C, Kosarussavadi B. Attenuation of the preoperative stress response with midazolam: Effects on postoperative outcomes. Anesthesiology 2000;93(1):141-7.

42. Sikandar S, Dickenson AH. Pregabalin modulation of spinal and brainstem visceral nociceptive processing. Pain 2011;152(10):2312-22.

43. Ha KY, Kim YH, Rhyu KW, Kwon SE. Pregabalin as a neuroprotector after spinal cord injury in rats. Eur Spine J $2008 ; 17(6): 864-72$. 